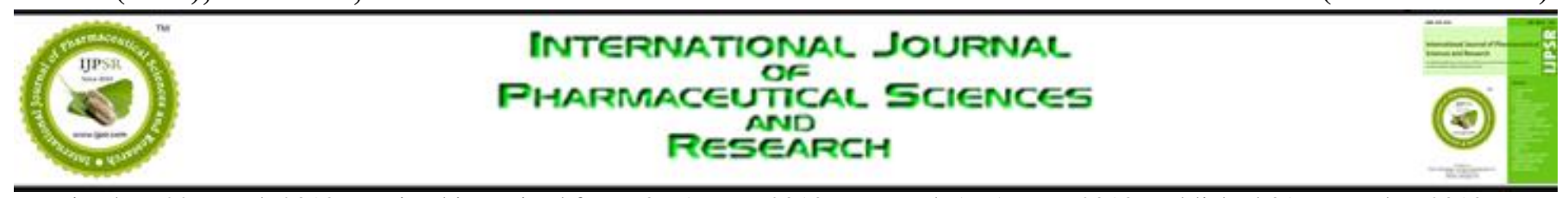

Received on 22 March 2018; received in revised form, 07 August 2018; accepted, 16 August 2018; published 01 December 2018

\title{
EPIDEMIOLOGY OF HEPATOCELLULAR CARCINOMA
}

\author{
Mohd. Aftab Siddiqui *, Hefazat Hussain Siddiqui, Anuradha Mishra and Afreen Usmani \\ Department of Pharmacology, Faculty of Pharmacy, Integral University, Lucknow - 226026, Uttar \\ Pradesh, India.
}

\section{Keywords:}

Hepatocellular carcinoma, Liver cancer, Etiologic factors, Hepatitis B

Correspondence to Author:

Prof. (Dr.) H. H. Siddiqui

Adjunct Professor,

Faculty of Pharmacy, Integral

University, Lucknow - 226026,

Uttar Pradesh, India.

E-mail: aftab.uzaiz@gmail.com

\begin{abstract}
Hepatocellular carcinoma (HCC) is a major cause of cancer death. Hepatocellular carcinoma (HCC) is the most common type of primary liver cancer. It is the fifth most common cancer worldwide and the third most common cause of cancer mortality. Despite advances in prevention techniques and new technologies in both diagnosis and treatment incidence and mortality continue to rise. It is less common in most parts of the developed Western world but appears to be increasing substantially in incidence. This malignancy occurs more often among men and older person. Rates of HCC are particularly high in Eastern / Southeastern Asia and Africa, intermediate in Southern Europe and low in most high-income countries. The most prominent risk factors for this cancer are hepatitis $\mathrm{B}$ virus (HBV) and hepatitis $\mathrm{C}$ virus (HCV). Some other factors are participating in a high incidence of $\mathrm{HCC}$ such as cirrhosis, cigarette smoking, alcohol drinking, obesity, aflatoxin exposure, familial/genetic factors, and metabolic disorders. The present review has aimed an overview of worldwide incidence, determinants or risk factors and distribution of HCC.
\end{abstract}

INTRODUCTION: The liver is the largest glandular organ in the body has more functions than any other body organ. The liver plays a major role in the maintenance of metabolic functions and detoxification of the exogenous and endogenous challenges like xenobiotic, drugs, viral infections and chronic alcoholism ${ }^{1}$. Chronic liver diseases are common disorders characterized by bad sequels started with steatosis to chronic hepatitis, fibrosis, cirrhosis, and hepatocellular carcinoma (HCC) ${ }^{2,3}$. Hepatocellular carcinoma (HCC) is the most common primary neoplasm of the liver. HCC is a significant cause of morbidity and mortality. It carries an unfavorable prognosis with aggressive growth behavior and a high rate of recurrence ${ }^{4,5}$.

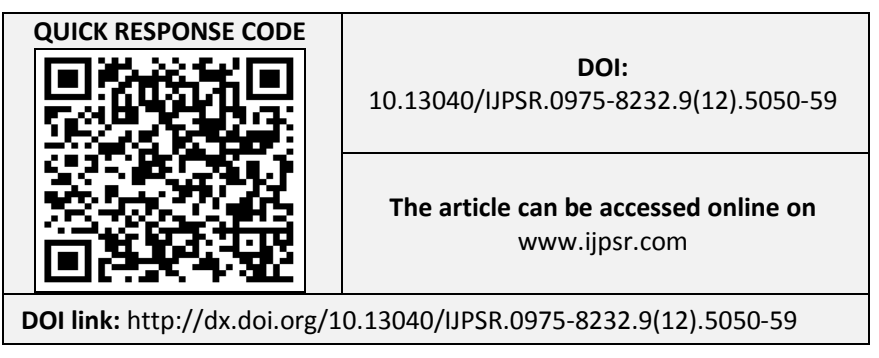

Hepatocellular carcinoma is the fifth most common cancer worldwide and the third leading cause of cancer-related deaths ${ }^{6,7,8}$. Hepatocellular carcinoma accounts for approximately $6 \%$ of all human cancers ${ }^{9}$. Since 1980 , the incidence of liver cancer has tripled. Liver cancer death rates have increased by almost $3 \%$ per year since $2000{ }^{10}$. Overall survival for patients diagnosed with $\mathrm{HCC}$ is generally dismal (1 and five year survival rates of $20 \%$ and $6 \%$, respectively) 11,12 .

For patients diagnosed with a small tumor and no distant spread, applying potentially curative therapy such as surgical resection, liver transplantation or local ablation significantly prolongs survival (40\%$50 \%$ at five years) ${ }^{13,14}$. It is often clinically silent until it is well advanced or tumor diameter exceeds $10 \mathrm{~cm}^{15}$. A large number of populations may remain asymptomatic. HCC patients may show jaundice, bloating from fluid in the abdomen, easy bruising from coagulopathy, loss of appetite, unintentional weight loss, nausea, vomiting or fatigue. 
Patients usually complain about right upper quadrant pain, weight loss, and deterioration of liver function in cirrhotic cases. Most symptoms are unspecific such as abdominal pain, malaise, fever, jaundice, anorexia, ascites, hemorrhage, and encephalopathy ${ }^{16}$. In most of the cases, cancer occurred in liver but did not begin there, rather are metastasized from anywhere in the body; such type of liver cancer is called secondary liver cancer. In Europe and United States secondary liver cancers are more frequent than primary liver cancer, but in Asia and Africa, primary liver cancer is more common cancer ${ }^{17}$. The most relevant risk factors for HCC are chronic Hepatitis B and Hepatitis C virus infection ${ }^{18,19}$.

Advanced ages, being male, obesity, alcohol abuse, diabetic and family history are also increased risks for developing $\mathrm{HCC}^{20} .70 \%-90 \%$ of patients have cirrhosis have HCC ${ }^{21}$. HCC screening includes radiologic tests such as ultrasound, computerized tomography, magnetic resonance imaging and serological markers such as $\alpha$-fetoprotein at 6month intervals. Multiple treatments available but only orthotopic liver transplantation (OLT) or surgical resection is curative. Additional treatment modalities include transarterial chemoembolization, radiofrequency ablation, microwave ablation, percutaneous ethanol injection, cryoablation, radiation therapy, systemic chemotherapy, and molecularly targeted therapies ${ }^{22}$. This article focuses on the epidemiology of hepatocellular carcinoma (HCC). It contains briefly reviews the incidence, the major distribution, and global determinants or risk factors of HCC.

Incidence: Over the past 20 years, the incidence of HCC has become doubled from 2.6 to 5.2 per 100,000 populations ${ }^{23}$. The incidence of HCC in developing nations is over twice the incidence of that in developed countries. The major risk factors for hepatocellular carcinoma vary by region and degree of national development ${ }^{24,25}$.

Asia: In India, the age-adjusted incidence rate of hepatocellular carcinoma (HCC) for men ranges from 0.7 to 7.5 and for women 0.2 to 2.2 per 100,000 of population per year. The agestandardized mortality rate for $\mathrm{HCC}$ in India for men is 6.8/100,000 and for women is 5.1/100,000. The incidence of HCC in cirrhotics in India is $1.6 \%$ per year. The incidence of $\mathrm{HCC}$ is increasing in India. The high incidence of $\mathrm{HCC}$ in India is related to cirrhosis of liver, chronic hepatitis $\mathrm{B}$ virus (HBV) infection, chronic hepatitis $\mathrm{C}$ virus (HCV) infection, alcohol consumption and aflatoxin exposure, diabetes mellitus, non-alcoholic fatty liver disease (NAFLD), smoking and tobacco use $^{26,27}$. More than half of HCCs occur in China alone wherein 2008 the age-standardized incidence rate was 37.4 per 100,000 individuals for males and 13.7 per 100,000 individuals for females. The incidence of HCC in Mongolia and Korea are also high with 99 and 49 cases per 100,000 persons respectively ${ }^{28}$. The high incidence of HCC in these areas is related to the high hepatitis $\mathrm{B}$ virus (HBV) infection rates in Asia and especially in China where HBV has traditionally been acquired via transmission from mother to child ${ }^{29,30}$. Japan also has a high incidence of HCC with a case index of approximately 40 per 100,000 populations. Hepatitis $\mathrm{C}$ virus (HCV) is the dominant hepatitis virus in Japan, accounting for $80 \%$ of HCC cases. The prevalence of HCV increased in Japan after World War II due to intravenous (IV) drug use as well as contaminated blood transfusion ${ }^{31,32}$.

Africa: In Africa first case of HCC was reported in 1879. Lack of screening and access to medical care is a major cause of death in the black African population. Whites living in the subcontinent have a low incidence of HCC. Most of these cases are found in rural areas. The age-standardized incidence rate in Mozambique (Africa) has the highest, recorded 41.2/100,000 persons each year. Chronic HBV infection is the major cause of HCC in Africa. Cirrhosis coexists with $\mathrm{HCC}$ is about $60 \%$ of patients in this region ${ }^{33,34}$.

The United States and Europe: In the United States, the overall incidence of HCC is lower than in other parts of the world. The age-adjusted incidence rate tripled from 1975 to 2005 from $1.6 / 100,000$ to $4.9 / 100,000$. This increase is likely a result of the increasing prevalence of $\mathrm{HCV}$ from unscreened blood transfusions and IV drug use. The incidence of HCC in the United States is expected to continue to increase over the next decade, because of peak HCV infection rates. HBV accounts for only $10 \%$ to $15 \%$ of $\mathrm{HCC}$ cases in the United States because of widespread HBV vaccination programs ${ }^{35}$. 
Europe has a slightly higher incidence (2-4 times) of HCC than the United States. The Mediterranean countries (Italy, Spain, and Greece) have incidence rates ranging from 10-20 per 100,000 individuals. These countries also attribute approximately twothirds of their cases to chronic HCV infection ${ }^{36,37}$.

The global burden of cancer in 2012 was an alltime high of 14 million cases and predicted to grow to 22 million over the next two decades ${ }^{38}$. Recently incidence in the United States has stabilized will little annual change in rate between 2009 and 2011. In contrast, incidence rates have declined in some Asian countries, Spain, and Italy. The decreasing incidence rates were seen China is likely due to programs to reduce aflatoxin B1 exposure and hepatitis B virus (HBV) transmission as well as other public health efforts ${ }^{36}$. In Japan, the decreasing incidence of $\mathrm{HCC}$ is related to declining rates of hepatitis $\mathrm{C}$ virus (HCV) infection in the population $^{39,40}$.

\section{Distribution of Hepatocellular Carcinoma:}

1. Geographic Distribution: The incidence of HCC varies widely by geographic location. The geographic distribution of HCC is highly uneven. Three geographic areas with different incidence rates (low, intermediate and high) have been recognized ${ }^{41}$. Most HCC cases $(>80 \%)$ occur in either sub-Saharan Africa or in Eastern Asia. China alone accounts for more than $50 \%$ of the world's cases ${ }^{42}$. High incidence regions (more than 15 cases per 100,000 populations per year) include sub-Saharan Africa, the People's Republic of China, Hong Kong, and Taiwan ${ }^{43}$. Intermediate incidence areas include Eastern and Western Europe, Thailand, Indonesia, Jamaica, Haiti, New Zealand, and Alaska. Low incidence areas (less than three cases per 100,000 per year) include North and South America, most of Europe, Australia and parts of the Middle East ${ }^{44}$.

2. Age: The incidence of HCC increases with age 45. HCC is considered a disease of older persons with a high incidence in people between 65 to 69 years old. However, the prevalence in young people has risen in recent years due to environmental risk factors at birth ${ }^{46}$. Various studies have also reported that age plays a contradictory role on the prognosis of HCC. Young patients had poorer survival rates than elderly patients. This reduction in survival resulted from a more advanced tumor stage at diagnosis even though they had a better liver function. Also, young patients tended to exhibit larger tumor sizes and poorer differentiation compared with older ones. Young patients have a better survival which is compensated by better liver function, more aggressive therapy, and faster recovery 47. Fibrolamellar type of HCC typically occurs in young patients $48,49,50$.

3. Race / Ethnicity: Racial / ethnic differences within multi-ethnic populations are also remarkable. In the United States between 2006 and 2010 incidence rate per 100,000 had highest in Asians / Pacific Islanders (11.7) followed by Hispanics (9.5), blacks (7.5), and finally whites (4.2). Rates of liver cancer among the same ethnicity also vary by geographic location. For example, liver cancer rates among Chinese populations outside China are lower than the rates reported by Chinese registries ${ }^{51}$. One study found that the age-adjusted incidence of $\mathrm{HCC}$ was highest among Asians $(8.4$ per 100,000) followed by blacks $(4.2$ per 100,000$)$ and whites $(2.2$ per 100,000$){ }^{52}$.

Another study reported a greater age-adjusted incidence of HCC among Hispanic men (3.29 per $100,000)$ and women $(1.23$ per 100,000$)$ compared with white men (1.82 per 100,000) and women $(0.60 \text { per } 100,000)^{53}$. Racial/ethnic differences are likely due to variability in the prevalence of risk factors between racial/ethnic groups and between geographic locations.

4. Sex: This malignancy occurs more often among men than women. Men have an incidence of 11.5 per 100,000 compared to 3.9 in women. Hepatocellular carcinoma death rates have also increased by $2.8 \%$ for males and $3.4 \%$ for females per year ${ }^{54}$. The explanation for this sex difference might be threefold: firstly, men could have higher rates of environmental exposure to liver carcinogens (such as smoking or alcohol) and hepatitis virus infections; secondly estrogen effects might suppress interleukin (Il)-6-mediated inflammation in women reducing both liver injury and compensatory proliferation; thirdly testosterone effects could increase androgen receptor signaling in men promoting liver cell proliferation 55,56 Experiments show a 2 to 8 -fold increase in $\mathrm{HCC}$ 
development in male mice. These data support the hypothesis that androgens influence HCC progression rather than sex-specific exposure to risk factors. No endogenous environmental factors that may affect male risk adversely include higher body mass index and higher levels of androgenic hormones $57,58,59$.

Determinants (Risk Factors) of Hepatocellular Carcinoma: Fibrosis and cirrhosis are typically precursors of $\mathrm{HCC}^{60}$. Furthermore, HCV and HBV are the major etiological agents that lead to the development of $\mathrm{HCC}^{61}$. Other risk factors include environmental toxins, hereditary hemochromatosis and cirrhosis ${ }^{62}$. Coexistence of etiologies such as hepatitis B virus (HBV) and HCV infection, HBV infection and aflatoxin $\mathrm{B} 1, \mathrm{HBV} / \mathrm{HCV}$ infection and alcohol or diabetes mellitus, HCV infection and liver steatosis increases the relative risk of HCC development ${ }^{63}$.

\section{Viral Infection:}

Hepatitis B Virus (HBV): HBV is a DNA virus with a circular genome that encodes structural and replicative viral proteins. Association of chronic $\mathrm{HBV}$ infection and HCC was first elucidated in 1981 by Beasely and colleague ${ }^{64}$. There are eight genotypes of HBV classified using the letters A to $\mathrm{H}$. Most studies have shown an association between genotype $\mathrm{C}$ and an increased risk of liver fibrosis and HCC ${ }^{65,66}$. Approximately 340,000 cases of liver cancer (54.4\% of cases globally) are attributed to HBV with the majority of these in Africa, Asia, and the Western Pacific region ${ }^{67}$.

Worldwide chronic hepatitis B contributes to the greatest number of HCC. Individuals that have chronic hepatitis B may develop HCC without evidence of cirrhosis ${ }^{68}$. The association between HBV and cancer varies greatly depending on the country and the types of laboratory tests used to diagnose the disease ${ }^{69,70,71}$. In West Africa, HBV infection is generally acquired between the ages of 1 and five years and viral replication declines rapidly after adolescence. In East Asia, HBV infection is acquired before the age of 1 year in the majority of cases, and active HBV replication continues until an advanced age; therefore the incidence of HCC continues to increase with age without reaching a plateau ${ }^{72}$. In western countries, $\mathrm{HBV}$ is mostly transmitted in adolescence and adulthood through high-risk behaviors such as intravenous drug use, sexual exposure or iatrogenic causes including blood transfusion, unsafe needle practices, invasive procedures, hemodialysis or organ transplantation ${ }^{73,74,75}$.

Hepatitis C Virus (HCV): $\mathrm{HCV}$ is a member of the Flaviviridae family of hepatotropic RNA viruses. Chronic HCV infection is a major cause of HCC in humans ${ }^{76}$. Approximately 195,000 cases of liver cancer $(31.1 \%$ of cases globally) are attributed to $\mathrm{HCV}^{77}$. It is a leading cause of chronic hepatitis, liver cirrhosis, and HCC worldwide. The combination of $\mathrm{HCV}$ and $\mathrm{HBV}$ infection appears to increase the risk of $\mathrm{HCC}^{78}$. There have been six major genotypes identified (genotypes HCV-1 to HCV-6) each with multiple subtypes (distinguished by lowercase letters). Genotype 1 ( $a$ and b) is the most common worldwide ${ }^{79}$. Some studies identified genotype $1 \mathrm{~b}$ with a high risk for $\mathrm{HCC}$ development ${ }^{80}$.

Patients with HCV infection and who have been alcohol abusers prove to develop more severe fibrosis and have higher rates of cirrhosis and HCC than non-drinkers ${ }^{81}$. The highest rates of chronic hepatitis $\mathrm{C}$ infection occur in Egypt (18\%) with lower rates occur in Europe $(0.5 \%-2.5 \%)$, the United States $(1.8 \%)$ and Canada $(0.8 \%)$. In Asia, the $\mathrm{HCV}$ infection rate is highest in Mongolia ${ }^{82}$. Hepatitis $\mathrm{C}$ virus is more commonly found in blacks and non-Hispanic whites ${ }^{83,84}$.

Having chronic hepatitis B infection increases the risk of developing liver cancer by 100 -fold and having chronic hepatitis $\mathrm{C}$ infection increases the risk by 17 -fold. Coinfection with $\mathrm{HBV}$ and $\mathrm{HCV}$ further increases the risk of HCC. HBV can cause liver cancer directly without causing cirrhosis. The hepatitis virus can mix its DNA with the DNA of a liver cell and cause mutations in its genes; thus mutations can lead a cell to lose control over its common function, reproduction and natural cell death, at last, it causes HCC. The risk of liver cancer is higher in heavy drinkers ${ }^{85,86}$.

\section{Toxins:}

Aflatoxin: Aflatoxin is a mycotoxin produced by the Aspergillus fungus. This fungus grows readily on foodstuffs such as corn and peanuts stored in warm, damp conditions ${ }^{87}$. There are four 
aflatoxins: B1, B2, G1, and G2. Aflatoxin B1 (AFB1) has been shown to be the most potent hepatic carcinogen. AF also appears to have a synergistic effect on $\mathrm{HCV}$-induced liver cancer ${ }^{88}$. It causes alterations in the hepatocyte DNA ${ }^{89}$. Aflatoxins can induce mutations of the p53tumor suppressor gene ${ }^{90}$. Individuals exposed to chronic HBV infection and AF has up to 30 times greater than the risk in individuals exposed to AF only ${ }^{91}$. The main site of metabolism of AFB1 is the liver but absorbed in the enterocytes of the small intestinal epithelium through the cytochrome $\mathrm{p} 450$ enzymes that activate AFB1 into aflatoxin-8, 9exo-epoxide that is highly reactive with the p53 tumor suppressor gene, generating mutation at codon 249 (R249S; 249ser mutation) in more than $50 \%$ of cases of HCC that were exposed to AFB1 92,93

Vinyl Chloride: A recent study reported long-term exposure to vinyl chloride is the identifiable risk factor for developing HCC. Angiosarcoma, hepatocarcinoma, and hepatoadenoma nodules were found in a worker who had been exposed to high doses of vinyl chloride for several years. An experimental study in rats shows angiosarcomas and hepatocarcinomas, the two types tumor found in the same animal after exposure to vinyl chloride ${ }^{94}$.

Contaminated Drinking Water: Several studies in rural China have noted a higher mortality rate from HCC among people who drink pond-ditch water compared to those who drink well water. The blue-green algal toxin microcystin commonly contaminates these ponds and is thought to be a strong promoter of $\mathrm{HCC}^{95}$.

Arsenic: Effects of arsenic on the liver have been suggested in a few case reports like noncirrhotic portal hypertension, hepatic enlargement, hepatocellular carcinoma, and liver angiosarcoma. Epidemiologic studies have not confirmed the association between arsenic exposure and hepatocellular carcinoma ${ }^{96}$.

\section{Personal Habits:}

Alcohol Drinking: The annual incidence of HCC in alcohol-related cirrhosis is $1-4 \%$. Alcoholic liver disease is the second most common risk factor for HCC in the USA after hepatitis $\mathrm{C}^{97}$. Heavy alcohol intake (more than 50-70 g/day) for prolonged periods is a well-established HCC risk factor.
Heavy intake is associated strongly with the development of cirrhosis.

Women are more susceptible than men to liver injury from alcohol intake ${ }^{98,99}$. Once alcoholic cirrhosis is established several factors further increase the risk of HCC; these include older age, male gender, and active infection with HBV or $\mathrm{HCV}$. Its first metabolite (acetaldehyde) is a local carcinogen in humans ${ }^{100}$. The main mechanisms of alcohol-induced HCC are acetaldehyde formation, cytochrome P4502E1 induction, reduced antioxidants, reduced retinoic acid, hypomethylation, iron overload, immune surveillance, neoangiogenesis, and inflammation ${ }^{101,102}$.

Smoking: Cigarette carries over 4000 toxic substances which cause hazardous adverse effects on almost every organ in the body. Several constituents of cigarette smoke are known liver carcinogens in humans and animal models, e.g. 4aminobiphenyl, arsenic, and vinyl chloride, etc. ${ }^{103}$ It is causally associated with liver cancer ${ }^{104}$. A meta-analysis reviewed the association between smoking and liver cancer demonstrated an odds ratio (OR) of 1.6 for current smokers and 1.5 for former smokers ${ }^{105}$. An Italian study reported that an interaction between tobacco smoking and infection with $\mathrm{HBV}$ and $\mathrm{HCV}$ could increase the risk of $\mathrm{HCC}^{106,107}$.

Betel Nut Chewing: Case-control trials have suggested that betel nut chewing, widespread in certain regions of Asia, may be an independent risk factor for cirrhosis and HCC ${ }^{108}$.

\section{Hereditary Diseases:}

Hereditary Hemochromatosis: Hereditary hemochromatosis $(\mathrm{HH})$ is an autosomic recessive disease in which an alteration in iron absorption, inducing deposition in the liver and other organs occur. Iron toxicity in the liver is produced by free radical formation, lipid peroxidation of cell organs causing cell death with fibrosis and cirrhosis ${ }^{109}$.

$\alpha$-1-antitrypsin Deficiency: $\alpha$-1-antitrypsin deficiency is an autosomic recessive disease with mutations in the gene A1AT causes an abnormal accumulation of $\alpha$-1-antitrypsin in the hepatocyte endoplasmic reticulum resulting in hepatic cells dysplasia and cirrhosis ${ }^{110}$. 
Wilson's Disease: Wilson's disease is a heritable disease with mutations in the gene ATP7B and alteration in plasma copper circulation and its bile excretion. Excessive free copper can provoke cytoplasmic injury, cirrhosis and sometimes HCC ${ }^{111}$.

\section{Hormone:}

Oral Contraceptive: A recent review of six studies showed a significant increase in HCC risk with a longer duration ( $>5$ years) of exposure to oral contraceptives ${ }^{112}$. Estrogen and progesterone components of oral contraceptive have been shown to induce and promote liver tumors in animals ${ }^{113}$. Estrogens are thought to cause liver neoplasia by increasing proliferation rates, thereby increasing rates of spontaneous mutations ${ }^{114}$. A series of case reports documented the occurrence of HCC in relatively young men who had been long-term users of androgenic steroids 115, 116, 117 .

Anabolic Steroids: Continuous use of anabolic androgenic steroid in high-doses is associated with substantial health risks, including hepatocellular adenoma. The malignant transformation from hepato-cellular adenoma to hepatocellular carcinoma $^{118}$.

\section{Diseases Related to Life Style:}

Obesity: Obesity is closely associated with hepatocellular carcinoma (HCC) as well as other malignancies. Obesity is an important risk factor for cancer development and overall mortality in HCC. Molecular mechanisms of hepatocarcinogenesis in obesity are adipose tissue remodeling, dysregulation of adipokines, increased reactive oxygen species, insulin resistance or hyperinsulinemia, alteration of gut microbiota, and dysregulation of microRNA. Obesity is the most common cause of non-alcoholic fatty liver disease (NAFLD) or non-alcoholic steatohepatitis (NASH). NAFLD or NASH leads to HCC as well as liver cirrhosis 119,120 .

Diabetes: Diabetes mellitus directly affects the liver because the liver plays an essential role in glucose metabolism. Diabetes is an independent risk factor for $\mathrm{HCC}^{121,122}$. Diabetes increases the risk of non-alcoholic fatty liver disease (NAFLD), a condition characterized by excess fat accumulation in the liver which ranges from isolated hepatic steatosis to more aggressive non- alcoholic steatohepatitis (NASH) and may progress then to fibrosis, cirrhosis, and eventually HCC ${ }^{123}$, 124

7. Cirrhosis of Liver: Cirrhosis occurs in $80-90 \%$ of HCC patients ${ }^{125}$. Cirrhosis is characterized by fibrous septae and nodule formation as well as alterations in blood flow. Hepatocellular carcinoma (HCC) can develop at any stage of cirrhosis ${ }^{126}$. The presence of cirrhosis of any cause increases the risk of HCC ${ }^{127}$. Main causes of liver cirrhosis are alcohol use, chronic hepatitis $\mathrm{B}, \mathrm{C}$ and nonalcoholic steatohepatitis ${ }^{128}$. A high rate of $\mathrm{HCC}$ has also been reported in patients with cirrhosis due to genetic hemochromatosis ${ }^{129}$ and primary biliary cirrhosis ${ }^{130}$. Different risk of HCC causes different rates of incidence: $\mathrm{HCV}>\mathrm{HBV}>$ hemochromatosis. The stage of cirrhosis is also significant in determining the risk of HCC development ${ }^{131,132}$.

CONCLUSION: HCC is a common malignancy worldwide. The principal causal factors for carcinogenesis are viral infections, hereditary diseases, chronic medical conditions like diabetes and personal habits like alcohol drinking, smoking, etc. A detailed understanding of these risk factors and distribution is necessary to improve the screening, prevention, early identification, and management of HCC.

ACKNOWLEDGEMENT: Authors are thankful to Integral University Lucknow for providing the necessary facilities required for successful completion of this work (IU/R\&D/2018-MCN 000278).

CONFLICT OF INTEREST: The authors declare no conflict of interest related to this manuscript.

\section{REFERENCES:}

1. Anand K and Lal UR: Hepatitis and medicinal plants: An overview. Journal of Pharmacognosy and Phytochemistry 2016; 5(6): 408-15.

2. Loguercio $\mathrm{C}$ and Federico A: Oxidative stress in viral and alcoholic hepatitis. Free Radical Biology and Medicine 2003; 34: 1-10

3. Vitaglione P, Morisco F, Caporaso $\mathrm{N}$ and Fogliano V: Dietary antioxidant compounds and liver health. Critical Reviews in Food Science and Nutrition 2004; 44: 575-86.

4. Poulou LS, Botsa E, Thanou I, Ziakas PD and Thanos L: Percutaneous microwave ablationvs radiofrequency ablation in the treatment of hepatocellular carcinoma. World Journal of Hepatology 2015; 7: 1054-63

5. Hetta OM, Shebrya NH and Amin SK: Ultrasound-guided microwave ablation of hepatocellular carcinoma: an Initial 
institutional experience. The Egyptian Journal of Radiology and Nuclear Medicine 2011; 42: 343-49.

6. Parkin DM, Bray F, Ferlay J, and Pisani P: Estimating the world cancer burden: Globocan. International Journal of Cancer 2001; 94: 153-56.

7. Njei B, Rotman Y, Ditah I and Lim JK: Emerging trends in hepatocellular carcinoma incidence and mortality. Hepatology 2015; 61: 191-9.

8. Atlanta, American Cancer Society. Cancer facts \& figures2016;172.(https://www.cancer.org/content/dam/can cer-org/research/cancer-facts-and-statistics/annual-cancerfacts-and-figures/2016/cancer-facts-and-figures-2016.pdf).

9. Liang TK, Jeffers LJ, and Reddy KJ: Viral pathogenesis of hepatocellular carcinoma in the United States. Hepatology 1993; 18: 1326-33.

10. https://www.cancer.net/cancer-types/liver-cancer/statistics

11. Ferlay J, Soerjomataram I and Dikshit R: Cancer incidence and mortality worldwide: sources, methods and major patterns in Globocan. Int J Cancer 2015; 136: E359-E86.

12. Maresso KC, Tsai KY, Brown PH, Szabo E, Lippman S and Hawk ET. Molecular cancer prevention: Current status and future directions. CA Cancer J Clin 2015; 65: 345-83.

13. El-Serag HB, Mason AC, and Key C: Trends in survival of patients with hepatocellular carcinoma between 1977-1996 in the United States. Hepatology 2001; 33: 62-5.

14. Liu JH, Chen PW, and Asch SM: Surgery for hepatocellular carcinoma: does it improve survival? Annals of Surgical Oncology 2004; 11: 298-03.

15. Silva $\mathrm{M}$ and Sherman M: Criteria for liver transplantation for HCC: What should the limits be? Journal of Hepatology 2011; 55(5): 1137-47.

16. Befeler AS and Di BisceglieAM: Hepatocellular carcinoma: diagnosis and treatment. Gastroenterology 2002; 122: 1609-19.

17. Usmani A and Mishra A: Current updates on risk factors of hepatocellular carcinoma. Res Rev 2017; 8: 23-31.

18. Chen CJ, Yang HI, Su J, Jen CL, You SL, Lu SN, Huang GT, and Iloeje UH: Risk of hepatocellular carcinoma across a biological gradient of serum hepatitis B virus DNA level. The Journal of the American Medical Association 2006; 295: 65-73.

19. Zamor PJ: Viral hepatitis and hepatocellular carcinoma: etiology and management. Journal of Gastrointestinal Oncology 2017; 8(2): 229.

20. Custer B, Sullivan SD, Hazlet TK, Iloeje U, Veenstra DL, and Kowdley KV: Global epidemiology of hepatitis B virus. Jour of Clinical Gastroenterology 2004; 38: S158-68

21. Chen G, Lin W, Shen F, Iloeje UH, London WT and Evans AA: Past HBV viral load as a predictor of mortality and morbidity from HCC and chronic liver disease in a prospective study. The American Jour of Gastroenterology 2006; 101: 1797-03.

22. Balogh J, Victor III D, Asham EH, Gordon S, Burroughs, Boktour M, Saharia A, Li X, Ghobrial RM, and Monsour HP: Hepatocellular carcinoma: A review. Journal of Hepatocellular Carcinoma 2016; 3: 41-53.

23. Bertuccio P, Turati F, Carioli G, Rodriguez T, La Vecchia $\mathrm{C}$ and Malvezzi $\mathrm{M}$ : Global trends and predictions in hepatocellular carcinoma mortality. J Hepatol 2017; 67: 302-09.

24. Bosch FX, Ribes J, and Diaz M: Primary liver cancer: worldwide incidence and trends. Gastroenterology 2004; 127(1): S5-16.

25. Ryerson AB, Eheman CR, Altekruse SF, Ward JW, Jemal A, and Sherman RL: Annual Report to the Nation on the Status of Cancer, 1975-2012, featuring the increasing incidence of liver cancer. Cancer 2016; 122: 1312-37.
26. Acharya SK: Epidemiology of hepatocellular carcinoma in India. Journal of Clinical and Experimental Hepatology 2014; 4: S27-S33.

27. Kumar A, Acharya SK and Singh SP: The Indian National Association for Study of the Liver (INASL) consensus on the prevention, diagnosis, and management of hepatocellular carcinoma in India: The Puri Recommendations. Journal of Clinical and Experimental Hepatology 2014; 4: S3-S26

28. Ferlay J, Shin HR, Bray F, Forman D, Mathers C, and Parkin DM: Estimates of worldwide burden of cancer in 2008: Globocan. International journal of cancer 2010; 127(12): 2893-917.

29. Shariff M, Cox I and Gomaa A: Hepatocellular carcinoma: current trends in worldwide epidemiology, risk factors, diagnosis, and therapeutics. Expert Review of Gastroenterology \& Hepatology 2009; 3(4): 353-67.

30. Custer B, Sullivan S and Hazlet T: Global epidemiology of hepatitis B virus. Journal of Clinical Gastroenterology 2004; 38(10): S158-68.

31. El-Serag HB and Rudolph KL: Hepatocellular carcinoma: epidemiology and molecular carcinogenesis. Gastroenterology 2007; 132(7): 2557-76.

32. Yoshizawa H: Hepatocellular carcinoma associated with hepatitis $\mathrm{C}$ virus infection in Japan: projection to other countries in the foreseeable future. Oncology 2002; 62 (S1): 8-17.

33. Kew M: Epidemiology of hepatocellular carcinoma in subSaharan Africa. Annals of Hepatology 2013; 12(2): 17382.

34. Yang JD, Mohamed EA, Aziz AO, Shousha HI, Hashem $\mathrm{MB}$, and Nabeel MM: Characteristics, management, and outcomes of patients with hepatocellular carcinoma in Africa: a multi-country observational study from the Africa Liver Cancer Consortium. Lancet Gastroenterol Hepatol 2017; 2: 103-11.

35. Mittal S and El-Serag H: Epidemiology of hepatocellular carcinoma: consider the population. Journal of Clinical Gastroenterology 2013; 47: S2-6.

36. Bosch F, Ribes $\mathrm{J}$, and $\mathrm{Cle}^{\prime}$ ries $\mathrm{R}$ : Epidemiology of hepatocellular carcinoma. Clinics in Liver Disease 2005; 9(2): 191-211.

37. White DL, Thrift AP, Kanwal F, Davila J, and El-Serag HB: Incidence of hepatocellular carcinoma in all 50 United States, from 2000 through 2012. Gastroenterology 2017; 152: 812-20.

38. Stewart BW and Wild CP: World Cancer Report 2014. Lyon, France: International Agency for Research on Cancer. World Health Organization 2014; 630.

39. Petrick JL, Kelly SP, Altekruse SF, McGlynn KA, and Rosenberg PS: Future of hepatocellular carcinoma incidence in the United States forecast through 2030. J Clin Oncol 2016; 34: 1787-94.

40. Mittal S, Kanwal F, Ying J, Chung R, Sada YH and Temple S: Effectiveness of surveillance for hepatocellular carcinoma in clinical practice: A United States cohort. J Hepatol 2016; 65: 1148-54.

41. Gao S, Yang WS and Bray F: Declining rates of hepatocellular carcinoma in urban Shanghai: incidence trends in 1976-2005. European Journal of Epidemiology 2012; 27(1): 39-46.

42. Tanaka H, Imai Y, and Hiramatsu N: Declining incidence of hepatocellular carcinoma in Osaka, Japan, from 1990 to 2003. Annals of Internal Medicine 2008; 148(11): 820-26.

43. Calvisi D, Evert M and Dombrowski F: Review Article Pathogenetic and Prognostic Significance of Inactivation 
of RASSF proteins in human hepatocellular carcinoma. Molecular Biology International 2012; 849-74.

44. Cabibbo $\mathrm{G}$ and Craxi A: Epidemiology, risk factors, and surveillance of hepatocellular carcinoma. European Review for Medical and Pharmacological Sciences 2010; 14: 352-55.

45. Parkin DM and Muir CS: Cancer Incidence in Five Continents. Comparability and quality of data. IARC scientific publications 1992; 120: 45-173.

46. Munoz N and Bosch X: Epidemiology of hepatocellular carcinoma. In Neoplasms of the Liver, Springer, Tokyo 1987; 3-19.

47. Ribes J, Cleries R, and Borras J: Time trends in incidence and mortality for chronic liver disease and liver cancer in the interval 1980-1997 in Catalonia, Spain. European Jour of Gastroenterology \& Hepatology 2004; 16: 856-72.

48. Gomaa A, Khan S, Toledano M, Waked I and TaylorRobinson S: Hepatocellular carcinoma: Epidemiology, risk factors, and pathogenesis. World Jour of Gastroenterology 2008; 14(27): 4300-08.

49. El-Serag HB and Mason AC: Rising incidence of hepatocellular carcinoma in the United States. The New England Journal of Medicine 1999; 340: 745-50.

50. Zhang $\mathrm{W}$ and Sun B: Impact of age on the survival of patients with liver cancer: an analysis of 27,255 patients in the SEER database. Oncotarget 2014; 6(2): 633-41.

51. Farhi DC, Shikes RH, Murari PJ, and Silverberg SG: Hepatocellular carcinoma in young people. Cancer 1983; 52: 1516-25.

52. Aramaki M, Kawano K, Sasaki A, Ohno T, Tahara K, Kai S, Iwashita Y and Kitano S: Hepatocellular carcinoma in young adults. Hepatogastroenterology 2005; 52: 1795-97.

53. Lack EE, Neave C, and Vawter GF: Hepatocellular carcinoma. Review of 32 cases in childhood and adolescence. Cancer 1983; 52: 1510-15.

54. McGlynna KA, Petricka JL, and London WT: Global epidemiology of hepatocellular carcinoma: an emphasis on demographic and regional variability. Clinics in Liver Disease 2015; 19(2): 223-38.

55. El-Serag HB, Davila JA, and Petersen NJ: The continuing increase in the incidence of hepatocellular carcinoma in the United States: an update. Annals of Internal Medicine 2003; 139: 817-23.

56. Shea KA, Fleming LE, and Wilkinson JD: Hepatocellular carcinoma incidence in Florida: ethnic and racial distribution. Cancer 2001; 91: 1046-51.

57. Recio-Boiles A and Babiker HM: University of Arizona Cancer Center. Stat Pearls Publishing, Treasure Island 2017; $1-13$.

58. Naugler WE, Sakurai T, Kim S, Maeda S, Kim K, Elsharkawy AM, and Karin M: Gender disparity in liver cancer due to sex differences in MyD88 dependent IL-6 production. Science 2007; 317(5834): 121-4.

59. Yu MW, Lin CL, Liu CJ, Yang SH, Tseng YL, and Wu $\mathrm{CF}$ : Influence of metabolic risk factors on risk of hepatocellular carcinoma and liver-related death in men with chronic hepatitis B: a large cohort study. Gastroenterology 2017; 153: 1006-17.

60. Yu MW and Chen CJ: Elevated serum testosterone levels and risk of hepatocellular carcinoma. Cancer Research 1993; 53: 790-94.

61. Rudolph KL, Chang S, Millard M, Schreiber-Agus N, and DePinho RA: Inhibition of experimental liver cirrhosis in mice by telomerase gene delivery. Science 2000; 287: 1253-58.

62. Seeff LB: Introduction: The burden of hepatocellular carcinoma. Gastroenterology 2004; 127: S1-S4,
63. Colombo M, Kuo G, and Choo Q: Prevalence of antibodies to hepatitis $\mathrm{C}$ virus in Italian patients with hepatocellular carcinoma. Lancet 1989; 2: 1006-8.

64. Davila JA, Morgan RO and Shaib Y: Hepatitis C infection and the increasing incidence of hepatocellular carcinoma: A population-based study. Gastroent 2004; 127: 1372.

65. Blum HE: Hepatocellular carcinoma: Therapy and prevention. World Journal of Gastroenterology 2005; 11(47): 7391-400.

66. Beasley R, Hwang L, and Lin C: Hepatocellular carcinoma and hepatitis B virus: a prospective study of 22,707 men in Taiwan. Lancet 1981; 2(8256): 1129-33.

67. McMahon B: The influence of hepatitis B virus genotype and subgenotype on the natural history of chronic hepatitis B. Hepatology International 2009; 3(2): 334-42.

68. Chan H, Hui A, and Wong M: Genotype C hepatitis B virus infection is associated with an increased risk of hepatocellular carcinoma. Gut 2004; 53(10): 1494-8.

69. Venook AP, Papandreou C, and Furuse J: The incidence and epidemiology of hepatocellular carcinoma: a global and regional perspective. Oncologist 2010; 15(4): 5-13.

70. Lavanchy D: Hepatitis B virus epidemiology, disease burden, treatment, and current and emerging prevention and control measures. Journal of Viral Hepatitis 2004; 11: 97-107.

71. Wang JH, Yen $\mathrm{YH}$, Yao CC, Hung $\mathrm{CH}$, Chen $\mathrm{CH}$, and $\mathrm{Hu}$ TH: Liver stiffness-based score in hepatoma risk assessment for chronic hepatitis $\mathrm{C}$ patients after successful antiviral therapy. Liver Int 2016; 36: 1793-99.

72. Lutwick L: Relation between aflatoxin, hepatitis-B virus, and hepatocellular carcinoma. Lancet 1979; 313: 755-7.

73. Evans AA, O'Connell AP, Pugh JC, Mason WS, Shen FM, Chen GC, Lin WY, Dia A, M'Boup S, Drame B, and London WT: Geographic variation in viral load among hepatitis B carriers with differing risks of hepatocellular carcinoma. Cancer Epidemiology, Biomarkers and Prevention 1998; 7(7): 559-65.

74. Yuen MF: Independent risk factors and predictive score for the development of hepatocellular carcinoma in chronic hepatitis B. Jour of Hepatology 2009; 50: 80-88.

75. Chen JG, Kuang SY, and Egner PA: Acceleration to death from liver cancer in people with hepatitis B viral mutations detected in plasma by mass spectrometry. Cancer Epidemiol Biomarkers Prev 2007; 16: 1213-17.

76. Yang HI: Nomograms for risk of hepatocellular carcinoma in patients with chronic hepatitis B virus infection. Journal of Clinical Oncology 2010; 28: 2437-44.

77. IARC: Monographs on the Evaluation of Carcinogenic Risks to Humans. Hepatitis Viruses. Lyon: International Agency for Research on Cancer 1994; 59.

78. Sanyal AJ, Yoon SK, and Lencioni R: The etiology of hepatocellular carcinoma and consequences for treatment. Oncologist 2010; 15(4): 14-22.

79. Bruix J, Calvet X, and Costa J: Prevalence of antibodies to hepatitis $\mathrm{C}$ virus in Spanish patients with hepatocellular carcinoma and hepatic cirrhosis. Lancet 1989; 2: 1004.

80. Zaltron S, Spinetti A and Biasi L: Chronic HCV infection: epidemiological and clinical relevance. BMC Infectious Diseases 2012; 12(2): S2-7.

81. Zein NN, Poterucha JJ, Gross JB, Jr., Wiesner RH, Therneau TM, Gossard AA, and Wendt NK: Increased risk of hepatocellular carcinoma in patients infected with hepatitis $\mathrm{C}$ genotype 1b. The American Journal of Gastroenterology 1996; 91: 2560-2.

82. Singal AK and Anand BS: Mechanisms of synergy between alcohol and hepatitis $\mathrm{C}$ virus. Journal of Clinical Gastroenterology 2007; 41(8): 761-72. 
83. Bostan $\mathrm{N}$ and Mahmood T: An overview of hepatitis C: a devastating virus. Critical Reviews in Microbiology 2010; 36(2): 91-133.

84. Okita K, Izumi N, Matsui O, Tanaka K, Kaneko S and Moriwaki H: Peretinoin after curative therapy of hepatitis C-related hepatocellular carcinoma: a randomized, doubleblind placebo-controlled study. J Gastroenterol 2015; 50: 191-202.

85. Selimovic D, El-Khattouti A, and Ghozlan H: Hepatitis C virus-related hepatocellular carcinoma: An insight into molecular mechanisms and therapeutic strategies. World J Hepatol 2012; 4(12): 342-55.

86. Wang TH, Chen TC, Teng X, Liang KH, and Yeh CT: Automated biphasic morphological assessment of hepatitis B-related liver fibrosis using second harmonic generation microscopy. Sci Rep 2015; 5: 12962.

87. Wong RJ and Corley DA: Survival differences by race/ethnicity and treatment for localized hepatocellular carcinoma within the United States. Digestive diseases and sciences 2009; 54(9): 20-31.

88. Overall evaluations of carcinogenicity an updating of IARC monographs. IARC Monographs 1987; 42(7): 8387.

89. Liu Y and Wu F: Global burden of aflatoxin-induced hepatocellular carcinoma: a risk assessment. Environmental Health Perspectives 2010; 118(6): 818-24

90. Bosch FX, Ribes J, Cleries R, and Diaz M: Epidemiology of hepatocellular carcinoma. Clinics in Liver Disease 2005; 9: 191-211.

91. Nakamoto Y, Guidotti LG, Kuhlen CV, Fowler P, and Chisari FV: Immune pathogenesis of hepatocellular carcinoma. Journal of Experimental Medicine 1998; 188: 341-50.

92. Groopman JD, Kensler TW, and Wild CP: Protective interventions to prevent aflatoxin-induced carcinogenesis in developing countries. Annual Review of Public Health 2008; 29: 187-203.

93. Hamid AS, Tesfamariam IG, and Zhang Y: AflatoxinB1induced hepatocellular carcinoma in developing countries: Geographical distribution, mechanism of action and prevention. Oncol Lett 2013; 5(4): 1087-92.

94. Lopez-Valdes S and Medinilla-Cruz M: The relationship of aflatoxinb1 and hepatocellular carcinoma: A mini review. Journal of Liver Research, Disorders \& Therapy 2017; 3(6): 73.

95. Mastrangelo G, Fedeli U, Fadda E, Valentini F, Agnesi R, Magarotto G, Marchì T, Buda A, Pinzani M, and Martines D: Increased risk of hepatocellular carcinoma and liver cirrhosis in vinyl chloride workers: synergistic effect of occupational exposure with alcohol intake. Environmental Health Perspectives 2004; 112(11): 1188.

96. Centeno JA, Mullick FG, Martinez L, Page NP, Gibb H, Longfellow D, Thompson C, and Ladich ER: Pathology related to chronic arsenic exposure. Environmental Health Perspectives 2002; 110(5): 883.

97. Lee FI: Cirrhosis and hepatoma in alcoholics. Gut 1966; 7 : 77-85.

98. Frezza M: High blood alcohol levels in women. The role of decreased gastric alcohol dehydrogenase activity and first-pass metabolism. The New England Journal of Medicine 1990; 322: 95-99.

99. Stickel F: Alcoholic cirrhosis and hepatocellular carcinoma. Adv Exp Med Biol 2015; 815: 113-30.

100. Donato F, Tagger A, and Gelatti U: Alcohol and hepatocellular carcinoma: the effect of lifetime intake and hepatitis virus infections in men and women. American Journal of Epidemiology 2002; 155(4): 323-31.
101. Sidharthan S and Kottilil S: Mechanisms of alcoholinduced hepatocellular carcinoma. Hepatol Int 2014; 8(2): 452-7.

102. Singal AG and El-Serag HB: Hepatocellular carcinoma from epidemiology to prevention: translating knowledge into practice. Clin Gastroenterol Hepatol 2015; 13: 2140 51.

103. International Agency for Research on Cancer (IARC). Personal Habits and Indoor Combustions. In a review of human carcinogens; IARC Monographs on the evaluation of carcinogenic risks to humans: Lyon, France, 2012; 100: 373-499.

104. Zhang XF, Wei T, Liu XM, Liu C, and Lv Y: Impact of cigarette smoking on the outcome of hepatocellular carcinoma after surgery in patients with hepatitis B. PloS One 2014; 9(1): e85077.

105. Chuang SC, La Vecchia C, and Boffetta P: Liver cancer: Descriptive epidemiology and risk factors other than HBV and HCV infection. Cancer Letters 2009; 286(1): 9-14.

106. Gandini S, Botteri E, Iodice S, Boniol M, Lowenfels AR, and Maisonneuve P: Tobacco smoking and cancer: a metaanalysis. International Jour of Cancer 2008; 122: 155-64.

107. Holland JF: Review: A Companion to Holland-Frei Cancer Medicine-5. BC Decker 2000

108. Franceschi S, Montella M, Polesel J, La Vecchia C, Crispo A, Dal Maso L, Casarin P, Izzo F, Tommasi L, Chemin I, Trépo C, Crovatto $M$ and Talamini R: Hepatitis viruses, alcohol, and tobacco in the etiology of hepatocellular carcinoma in Italy. Cancer Epidemiology, Biomarkers \& Prevention 2006; 15(4): 683-89.

109. Tsai JF, Chuang, LY, Jeng, and JE: Bquid chewing as a risk factor for hepatocellular carcinoma: A case-control study. British Journal of Cancer 2001; 84: 709.

110. Antoury C, Lopez R, Zein N, Stoller JK, and Alkhouri N: Alpha-1 antitrypsin deficiency and the risk of hepatocellular carcinoma in end-stage liver disease. World Journal of Hepatology 2015; 7(10): 1427.

111. Gunjan D, Nadda N, Kedia S, Nayak B, Paul SB, Gamanagatti SR, and Acharya SK: Hepatocellular carcinoma: An unusual complication of longstanding wilson disease. Journal of Clinical and Experimental Hepatology 2017; 7(2): 152-4.

112. Bailey MA and Brunt EM: Hepatocellular carcinoma: predisposing conditions and precursor lesions. Gastroenterology Clinics of North America 2002; 31: 641-62.

113. Maheshwari S, Sarraj A, Kramer J, and El-Serag HB: Oral contraception and the risk of hepatocellular carcinoma. Journal of Hepatology 2007; 47: 506-13.

114. Yu MC and Yuan JM: Environmental factors and risk for hepatocellular carcinoma. Gastroenterology 2004; 127(5): S72-S78.

115. De BV, Welsh JA, Yu MC, and Bennett WP: p53 mutations in hepatocellular carcinoma related to oral contraceptive use. Carcinogenesis 1996; 17: 145-49.

116. Johnson FL, Feagler JR, and Lerner KG: Association of androgenic-anabolic steroid therapy with the development of hepatocellular carcinoma. Lancet 1972; 1273-6.

117. Farrell GC, Joshua DE, Uren RF, Baird PJ, Perkins KW, and Kronenberg H: Androgen-induced hepatoma. Lancet 1975; 430-2.

118. Solbach P, Potthoff A, Raatschen HJ, Soudah B, Lehmann U, Schneider A, Gebel MJ, Manns MP and Vogel A: Testosterone-receptor positive hepatocellular carcinoma in a 29-year old bodybuilder with a history of anabolic androgenic steroid abuse: a case report. BMC Gastroenterology 2015; 15(1): 60 . 
119. Boyd PR and Mark GJ: Multiple hepatic adenomas and hepatocellular carcinoma in a man on oral methyltestosterone for eleven years. Cancer 1977; 40: 1765-70.

120. Charrez B, Qiao L, and Hebbard L: Hepatocellular carcinoma and non-alcoholic steatohepatitis: The state of play. World J Gastroenterol 2016; 22(8): 2494-02.

121. Sohn W: Obesity and hepatocellular carcinoma. Journal of Liver Cancer 2016; 16(2): 86-91.

122. Gao C, Fang L, Zhao HC, Li JT, and Yao SK: Potential role of diabetes mellitus in the progression of cirrhosis to hepatocellular carcinoma: a cross-sectional case-control study from Chinese patients with HBV infection. Hepatobiliary \& Pancreatic Diseases International 2013; 12(4): 385-93.

123. Wang C, Wang X, and Gong G: Increased risk of hepatocellular carcinoma in patients with diabetes mellitus: A systematic review and meta-analysis of cohort studies. International Journal of Cancer 2012; 130(7): 1639-48.

124. Mantovani A and Targher G: Type 2 diabetes mellitus and risk of hepatocellular carcinoma: spotlight on nonalcoholic fatty liver disease. Annals of translational medicine 2017; 5(13): 270-81.

125. Baffy G, Brunt EM, and Caldwell SH: Hepatocellular carcinoma in non-alcoholic fatty liver disease: an emerging menace. Jour of Hepatology 2012; 56: 1384e91.
126. Nordenstedt H, White DL, and El-Serag HB: The changing pattern of epidemiology in hepatocellular carcinoma. Digestive and Liver Disease 2010; 42(3): 206-14.

127. Pinter M, Trauner M, Peck-Radosavljevic M, and Sieghart W: Cancer and liver cirrhosis: implications for prognosis and management. ESMO Open 2016; 1(2): 42.

128. Chiesa R, Donato F, Tagger A, Favret M, Ribero ML, Nardi G, Gelatti U, Bucella E, Tomasi E, Portolani N, Bonetti M, Bettini L, Pelizzari G, Salmi A, Savio A, Garatti $\mathrm{M}$ and Callea F: Etiology of hepatocellular carcinoma in Italian patients with and without cirrhosis. Cancer Epidemiology, Biomarkers \& Preven 2000; 9: 213.

129. Raphael S, Yangde Z and YuXiang C: Hepatocellular Carcinoma: Focus on different aspects of management. ISRN Oncology 2012; 1-12.

130. Fargion S, Fracanzani AL, Piperno A, Braga M, D'Alba R, Ronchi G and Fiorelli G: Prognostic factors for hepatocellular carcinoma in genetic hemochromatosis. Hepatology 1994; 20: 1426-31.

131. Caballeria L, Pares A, Castells A, Gines A, Bru C and Rodes J: Hepatocellular carcinoma in primary biliary cirrhosis: similar incidence to that in hepatitis $\mathrm{C}$ virusrelated cirrhosis. The American Jour of Gastroenterology 2001; 96: 1160-63.

132. Fattovich G, Stroffolini T and Zagni I: Hepatocellular carcinoma in cirrhosis: incidence and risk factors. Gastroenterology 2004; 127(5): 35-50.

How to cite this article:

Siddiqui MA, Siddiqui HH, Mishra A and Usmani A: Epidemiology of hepatocellular carcinoma. Int J Pharm Sci \& Res 2018; 9(12): 5050-59. doi: 10.13040/IJPSR.0975-8232.9(12).5050-59.

All ๑ 2013 are reserved by International Journal of Pharmaceutical Sciences and Research. This Journal licensed under a Creative Commons Attribution-NonCommercial-ShareAlike 3.0 Unported License.

This article can be downloaded to ANDROID OS based mobile. Scan QR Code using Code/Bar Scanner from your mobile. (Scanners are available on Google Play store) 